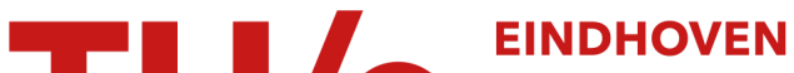 UNIVERSITY OF TECHNOLOGY
}

\section{Structure and soft magnetic properties of sputter deposited MnZn-ferrite films}

\section{Citation for published version (APA):}

Gillies, M. F., Coehoorn, R., van Zon, J. B. A. D., \& Alders, D. (1998). Structure and soft magnetic properties of sputter deposited MnZn-ferrite films. Journal of Applied Physics, 83(11), 6855-6857.

https://doi.org/10.1063/1.367866

DOI:

10.1063/1.367866

Document status and date:

Published: 01/01/1998

\section{Document Version:}

Publisher's PDF, also known as Version of Record (includes final page, issue and volume numbers)

\section{Please check the document version of this publication:}

- A submitted manuscript is the version of the article upon submission and before peer-review. There can be important differences between the submitted version and the official published version of record. People interested in the research are advised to contact the author for the final version of the publication, or visit the $\mathrm{DOI}$ to the publisher's website.

- The final author version and the galley proof are versions of the publication after peer review.

- The final published version features the final layout of the paper including the volume, issue and page numbers.

Link to publication

\section{General rights}

Copyright and moral rights for the publications made accessible in the public portal are retained by the authors and/or other copyright owners and it is a condition of accessing publications that users recognise and abide by the legal requirements associated with these rights.

- Users may download and print one copy of any publication from the public portal for the purpose of private study or research.

- You may not further distribute the material or use it for any profit-making activity or commercial gain

- You may freely distribute the URL identifying the publication in the public portal.

If the publication is distributed under the terms of Article $25 \mathrm{fa}$ of the Dutch Copyright Act, indicated by the "Taverne" license above, please follow below link for the End User Agreement:

www.tue.nl/taverne

Take down policy

If you believe that this document breaches copyright please contact us at:

openaccess@tue.nl

providing details and we will investigate your claim. 


\section{Structure and soft magnetic properties of sputter deposited MnZn-ferrite films}

M. F. Gillies, ${ }^{\text {a) }}$ R. Coehoorn, and J. B. A. van Zon

Philips Research, Prof. Holstlaan 4, 5656 AA Eindhoven, The Netherlands

D. Alders

Department of Physics, Eindhoven University of Technology, P.O. Box 513, 5600 MB Eindhoven, The Netherlands

In this paper we report the soft magnetic properties of thin films of sputtered MnZn ferrite deposited on thermally oxidized Si substrates. A high deposition temperature, $600{ }^{\circ} \mathrm{C}$, together with the addition of water vapor to the sputtering gas was found to improve the initial ac permeability, $\mu$. The highest value obtained was approximately 30. For MnZn-ferrite films with much larger grain sizes, as obtained by deposition on a polycrystalline Zn-ferrite substrate, a $\mu$ of 100 was obtained. The results are discussed in terms of the so-called nonmagnetic grain boundary model. (C) 1998 American Institute of Physics. [S0021-8979(98)53211-2]

\section{INTRODUCTION}

The growth of thin layers of magnetically soft ferrites such as MnZn or NiZn ferrite has been studied recently by various groups. ${ }^{1-3}$ This interest is motivated by potential applications such as magnetic thin-film read heads, ${ }^{4}$ cladding layers for thin film inductors, ${ }^{5}$ and microwave acoustic devices. $^{2}$ For most applications, two of the most important parameters are the resistivity of the layer and the ac permeability, $\mu$. While the resistivity is similar to that of the bulk the permeability of the thin ferrite films, on which many authors do not report explicitly, appears to be significantly less. This may be deduced from previously published $M$ vs $H$ loops $^{2}$ where, even when grown epitaxially, the films lack the true softness which characterizes the bulk material.

It has been shown by other authors that the addition of oxygen during deposition can have the effect of improving the softness of a thin film MnZn ferrite. ${ }^{1}$ We however, found that this can easily lead to an undesired oxygen rich ferrite. In the case of $\mathrm{Fe}_{3} \mathrm{O}_{4}$ it was found that the exact oxidation state of sputtered films could be more accurately controlled using $\mathrm{H}_{2} \mathrm{O} .{ }^{6}$ In this paper we report the effects on the soft magnetic properties of $\mathrm{MnZn}$ ferrite when a small amount of water vapor is added to the sputtering gas.

\section{EXPERIMENT}

The films were deposited in a Perkin Elmer 2400-8L rf diode sputter system, using Ar at a constant pressure of 0.29 $\mathrm{Pa}$ (2.2 mTorr). The background pressure was approximately $1.3 \times 10^{-4} \mathrm{~Pa}$. The substrate temperature during deposition was monitored by a thermocouple inserted into the substrate table and silver paste was used to ensure a good thermal contact. The films were sputtered from a $10 \mathrm{~cm}$ diameter $\mathrm{Mn}_{0.51} \mathrm{Zn}_{0.42} \mathrm{Fe}_{2.03} \mathrm{O}_{4}$ polycrystalline ferrite target which has a bulk $\mu$ of approximately 4000 . The deposition rate was 0.2 $\mu \mathrm{m} / \mathrm{h}$, with a rf power of $250 \mathrm{~W}$, and the films, which were grown on $\mathrm{Si}$ substrates with a $0.5 \mu \mathrm{m}$ pregrown thermal $\mathrm{SiO}_{2}$

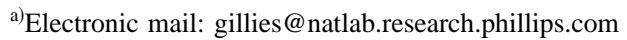

layer, were approximately $0.9 \mu \mathrm{m}$ thick. The initial ac permeability was measured $^{7}$ using an HP4129A analyzer with an applied ac field of $2.5 \mathrm{~A} / \mathrm{m}$.

\section{MAGNETIC PROPERTIES}

The magnetic properties were studied as a function of two deposition parameters: additional water vapor in the sputtering chamber and substrate temperature. The effect of the presence of an additional amount of water vapor on the soft magnetic properties is shown, for three different substrate temperatures, $T_{s}$, in Figs. 1(a)-1(c). In the case of no additional added water vapor, $\left[p\left(\mathrm{H}_{2} \mathrm{O}\right)=1.3 \times 10^{-4} \mathrm{~Pa}\right]$ an increase in $T_{s}$ does have an effect on $\mu$, though the maximum value attained was only 16 . Upon increasing $p\left(\mathrm{H}_{2} \mathrm{O}\right)$ the coercivity $H_{c}$ [Fig. 1(a)] is reduced, and for a $T_{s}$ of 550 or $600{ }^{\circ} \mathrm{C} H_{c}$ is approximately $1.6 \mathrm{kA} / \mathrm{m}$ with the addition of $0.13 \mathrm{~Pa}$ of $\mathrm{H}_{2} \mathrm{O}$. For $T_{s}=500{ }^{\circ} \mathrm{C}$ the minimum $H_{c}$ is approximately $2.8 \mathrm{kA} / \mathrm{m}$.

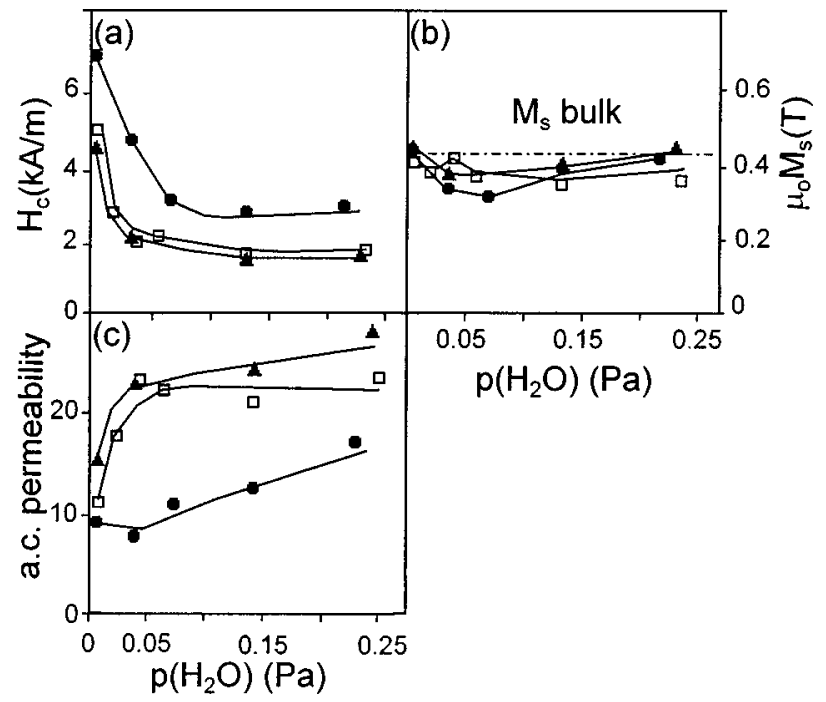

FIG. 1. The effect of the partial water-vapor pressure during sputtering on (a) the coercive field, (b) the saturation magnetization, and (c) the ac permeability of thin ferrite films. Deposited at $500{ }^{\circ} \mathrm{C}$ (circles), $550{ }^{\circ} \mathrm{C}$ (squares), and $600{ }^{\circ} \mathrm{C}$ (triangles). 


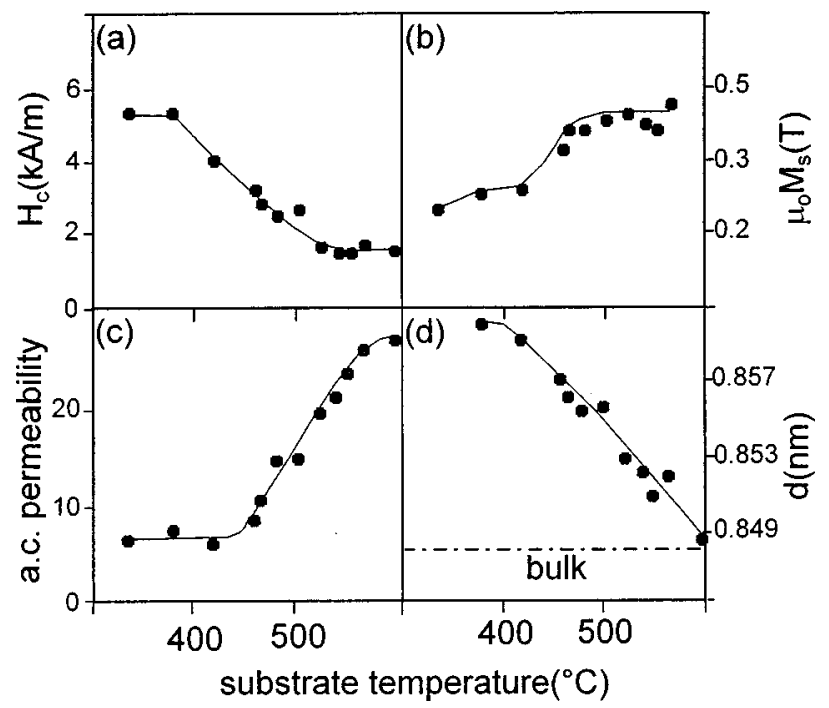

FIG. 2. The effect of a variation in substrate temperature at $p\left(\mathrm{H}_{2} \mathrm{O}\right)=0.13 \mathrm{~Pa}$ on (a) the coercive field, (b) the saturation magnetization, (c) the ac permeability, and (d) the lattice parameter of a $0.9 \mu \mathrm{m} \mathrm{MnZn-}$ ferrite film.

The room temperature saturation magnetization, $\mu_{0} M_{s}$, of the sputtered films, Fig. 1(b), is only slightly lower than that of the bulk material $(0.44 \mathrm{~T})$.

The ac permeability did not show any rolloff in the 1-13 $\mathrm{MHz}$ frequency range and the average value of permeability over this frequency range is what is given in Fig. 1(c). For the different $T_{s}$ the trend is similar: an increasing $p\left(\mathrm{H}_{2} \mathrm{O}\right)$ leads to a higher $\mu$, with the maximum, $\mu \approx 27$, being achieved with a $T_{s}$ of $600{ }^{\circ} \mathrm{C}$ and a $p\left(\mathrm{H}_{2} \mathrm{O}\right)$ of $0.23 \mathrm{~Pa}$.

While the trends in magnetic properties are independent of $T_{s}$ the actual values of $H_{c}$ and $\mu$ are not. The magnetic and structural properties (Sec. IV) of the sputtered ferrite were therefore measured for a new series of films where $T_{s}$ was varied while holding the $p\left(\mathrm{H}_{2} \mathrm{O}\right)$ constant at $0.13 \mathrm{~Pa}$. Figure 2(a) shows the influence of temperature on $H_{c}$ which falls to approximately $1.4 \mathrm{kA} / \mathrm{m}$ for $T_{s}$ higher than $560{ }^{\circ} \mathrm{C}$. An increase in $T_{s}$ also leads to an increase in the $\mu_{0} M_{s}$, Fig. 2(b). Substrate temperatures which are less than $450{ }^{\circ} \mathrm{C}$, result in a $\mu$ below 10, Fig. 2(c). Above $450{ }^{\circ} \mathrm{C} \mu$ increases rapidly with increasing temperature and at $600{ }^{\circ} \mathrm{C} \mu$ is approximately 27 .

\section{STRUCTURAL PROPERTIES}

The structural properties of the ferrite were also studied both as a function of $p\left(\mathrm{H}_{2} \mathrm{O}\right)$ and $T_{s}$. The width and position of the strongest peak, (400), in the $\theta-2 \theta \mathrm{Cu} K \alpha$ x-ray spectra did not show any relation to $p\left(\mathrm{H}_{2} \mathrm{O}\right)$ (while $T_{s}$ was fixed). The stoichiometry of these films, together with those deposited with various substrate temperatures, was checked using x-ray fluorescence, XRF, and electron probe microanalysis, EPMA. For depositions at $T_{s}$ less than $500{ }^{\circ} \mathrm{C}$ the composition did not appear to be influenced by $p\left(\mathrm{H}_{2} \mathrm{O}\right)$ and was, within experimental error, the same as the target material. For depositions at higher $T_{s}$ films showed $\mathrm{Zn}$ deficiency if deposited without $\mathrm{H}_{2} \mathrm{O}$. The fact that this did not occur in the presence of $\mathrm{H}_{2} \mathrm{O}$ may be due to the oxidation of metallic $\mathrm{Zn}$ on the surface of the film which would slow
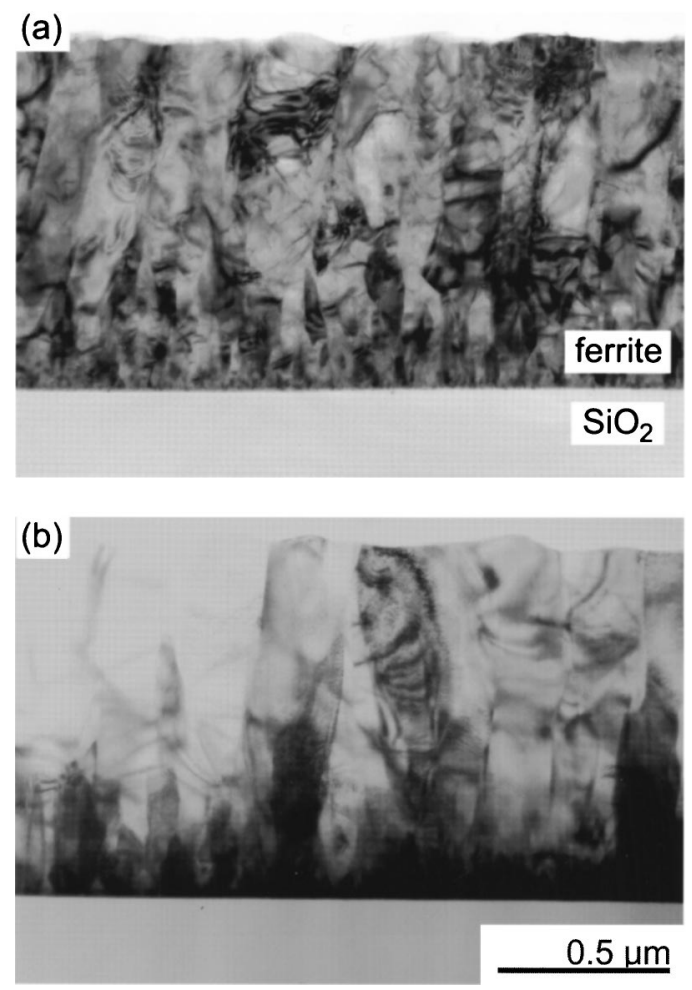

FIG. 3. TEM cross sections of films deposited at (a) $523{ }^{\circ} \mathrm{C}$ and (b) $604{ }^{\circ} \mathrm{C}$.

down any evaporation. For films with a reasonably high $\mu$, such as those deposited at $550{ }^{\circ} \mathrm{C} / 0.13 \mathrm{~Pa}$ water vapor, the stoichiometry was, within experimental error, the same as the target.

From the (400) x-ray diffraction peak positions the lattice parameter perpendicular to the film was determined for films deposited at different $T_{s}$, Fig. 2(d). The bulk (target) lattice parameter was $0.848 \mathrm{~nm}$. These experiments, as well as $\mathrm{x}$-ray measurements with a varying direction of the scattering vector and mechanical stress measurements, reveal a reduction in stress for increasing $T_{s}$. Due to the strain present in the ferrite films it is not possible to accurately determine the average crystal size via the analysis of x-ray peak widths. This was therefore determined via transmission electron microscopy (TEM) cross sections for films deposited at $T_{s}=523,565$, and $604{ }^{\circ} \mathrm{C}$. [The cross sections shown here are only for films deposited at 523 and $604{ }^{\circ} \mathrm{C}$ (Figs. 3(a) and 3(b), respectively).] While it is possible to discern a columnar structure within all the films it is clear that for a higher deposition temperature the columnar structure is more clearly defined. For the film deposited at $T_{s}=523{ }^{\circ} \mathrm{C}$ there exist imperfections throughout the whole thickness of the film. This is in contrast to films deposited at a higher $T_{s}$ where the formation of small crystallites only occurs during the initial stage of growth. In the later stages of growth a very distinct columnar structure appears. From the TEM cross sections the estimated average grain sizes for the depositions at 523,565 , and $604{ }^{\circ} \mathrm{C}$ were 90,110 , and $175 \mathrm{~nm}$, respectively.

\section{FILMS GROWN ON A Zn-FERRITE SUBSTRATE}

In Sec. IV the values for the approximate grain size of the ferrite films, as determined through TEM, were reported. 
From the nonmagnetic grain boundary model ${ }^{8}$ (NMGB model) the relationship between the effective initial permeability, $\mu_{e}$, the average grain size, $D$, and the intrinsic permeability, $\mu_{i}$, of the ferrite within a grain is given by

$$
\mu_{e}=\frac{\mu_{i} D}{\mu_{i} \delta+D},
$$

where $\delta$ is the width of the nonmagnetic grain boundary zone. Equation (1) implies that that for fixed values of $\delta$ and $\mu_{i}, \mu_{e}$ can be increased by increasing the grain size. We therefore increased the in-plane grain size of the MnZnferrite films by growing on a mechanically polished polycrystalline $\mathrm{Zn}$-ferrite $\left(\mathrm{ZnFe}_{2} \mathrm{O}_{4}\right)$ substrate with a grain size of approximately $15 \mu \mathrm{m}$. Since the lattice parameter mismatch is less than $0.5 \%$ and the thermal expansion coefficients are similar, ${ }^{9} \mathrm{Zn}$ ferrite is an ideal substrate on which to grow MnZn ferrite. On account of the substrate being paramagnetic at room temperature the magnetic properties of a MnZn-ferrite film can be measured without a contribution from the substrate. Figure 4 shows a scanning electron microscope photograph of a $0.9 \mu \mathrm{m}$ thick MnZn-ferrite film, deposited with $p\left(\mathrm{H}_{2} \mathrm{O}\right)=0.13 \mathrm{~Pa}$ and $T_{s}=560{ }^{\circ} \mathrm{C}$. As can be seen the in-plane grain size is around $15 \mu \mathrm{m}$. The film had a $H_{c}$ of less than $0.1 \mathrm{kA} / \mathrm{m}$ and was therefore much softer than those deposited on the $\mathrm{Si} / \mathrm{SiO}_{2}$ substrates $\left(H_{c} \approx 1.4 \mathrm{kA} / \mathrm{m}\right.$ for films deposited under identical conditions on $\mathrm{Si} / \mathrm{SiO}_{2}$ ). The ac permeability of the films deposited on $\mathrm{Zn}$ ferrite was $100 \pm 5$.

\section{DISCUSSION AND CONCLUSIONS}

The improvement in soft magnetic properties by adding water vapor to the sputtering gas was an unexpected result, for which we do not yet have an explanation. We did, however, consider the possibility that the presence of $\mathrm{H}_{2} \mathrm{O}$ affects the oxidation state of either the $\mathrm{Fe}$ or $\mathrm{Mn}$ ions in the ferrite. Using a wet chemical technique it was found that the fraction of $\mathrm{Fe}^{2+}$ and $\mathrm{Mn}^{3+}$ ions in the films, with and without water vapor, were very similar to that of the target. It could, however, still be possible that the concentration of either $\mathrm{Fe}^{2+}$ or $\mathrm{Mn}^{3+}$ ions at the grain boundaries is not as in the bulk material and, since these ions can give rise to a large single ion anisotropy in the presence of a crystal field, this could result in grain boundaries with a high anisotropy. The effect of high anisotropy grain boundaries was considered by Pankert ${ }^{10}$ and leads to a reduction in permeability.

The effect of the substrate temperature on the soft magnetic properties, which was also observed for films grown on the $\mathrm{Zn}$ ferrite, must be related to the increased mobility of the atoms when they arrive at the surface. This has the obvious effect of increasing the grain size which, according to the NMGB model, leads to a magnetically softer film. A higher temperature would also reduce the density of dislocations and other imperfections in the bulk of the grains and could reduce the thickness of the nonmagnetic grain boundary, thereby improving the softness of the ferrite.

The reduction in lattice parameter for increasing $T_{s}$, Fig. 2(d), is indicative of a lowering in the total stress which is present in these films (this was also checked using mechani-

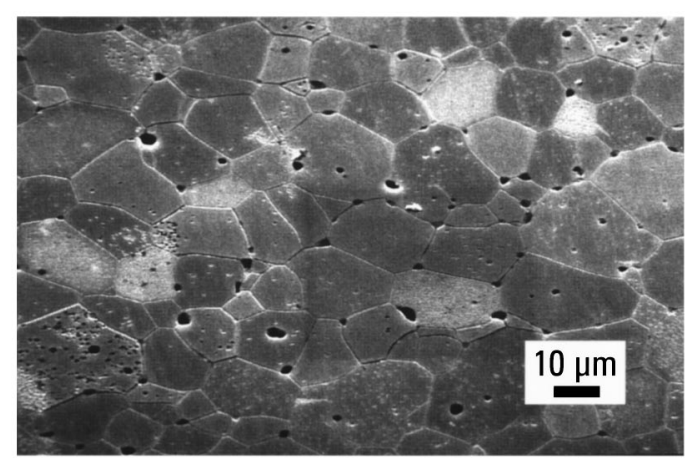

FIG. 4. SEM photograph of $0.9 \mu \mathrm{m} \mathrm{MnZn-ferrite} \mathrm{film} \mathrm{deposited} \mathrm{on} \mathrm{a} \mathrm{Zn-}$ ferrite substrate.

cal stress measurements). Taking the sign of the thermal mismatch between the substrate and the film into account such a behavior cannot be explained in terms of a thermal mismatch alone and there must exist excessive stress within the ferrite film itself. A shift in the lattice parameter, with respect to that of the bulk, is also observed for the MnZn-ferrite film deposited on $\mathrm{Zn}$ ferrite. A lowering of total stress for higher deposition temperatures may be responsible, at least in part, for the higher permeability achieved with these temperatures.

As would be expected from the NMGB model the choice of $\mathrm{Zn}$ ferrite as a substrate and the consequently larger grain size of the MnZn-ferrite film lead to a higher permeability. If, however, one substitutes into Eq. (1) the average grain size of the film shown in Fig. 4, together with a nonmagnetic grain-boundary thickness of a few nanometers (for the bulk a value of $1.4 \mathrm{~nm}$ has been determined ${ }^{8}$ ) then $\mu_{i} \approx \mu_{e}$, where $\mu_{e}$ has been found to be approximately 100 . Such a low value of $\mu_{i}$ may be caused by the presence of residual stress in the films though it is important to realize that the cation distribution was not checked in these sputtered layers and that a deviation from the desired distribution could also result in a low $\mu$.

A permeability of 30 , as obtained for thin films on $\mathrm{Si} / \mathrm{SiO}_{2}$ is sufficient to utilize these layers as cladding layers for thin film inductors. As a flux guide material in yoke-type thin film read heads ${ }^{4}$ a permeability of 30 is not quite sufficient. Further effort is therefore needed to realize a higher permeability and a lower deposition temperature.

\section{ACKNOWLEDGMENTS}

The authors would like to thank J. Daams, J. Donkers, M. A. Verheijen, and K. van de Aker for their X-ray and TEM work.

${ }^{1}$ C. M. Williams, D. B. Chrisey, P. Lubitz, K. S. Grabowski, and C. M. Cotell, J. Appl. Phys. 75, 1676 (1994).

${ }^{2}$ Y. Suzuki et al., Appl. Phys. Lett. 68, 714 (1996).

${ }^{3}$ H. Mikami, Y. Nishikawa, and Y. Omata, Conf. Proc. Int. Conf. Ferrites 7, 126 (1996).

${ }^{4}$ P. J. van der Zaag, J. M. M. Ruigrok, and M. F. Gillies, Philips J. Res. 51 (1998).

${ }^{5}$ W. A. Roshen, IEEE Trans. Magn. 26, 2880 (1990).

${ }^{6}$ Z. Zhou et al., J. Magn. Magn. Mater. 115, 87 (1992).

${ }^{7}$ J. P. C. Bernards, IEEE Trans. Magn. 30, 4881 (1994).

${ }^{8}$ P. J. van der Zaag, J. Appl. Phys. 74, 4085 (1993).

${ }^{9}$ K. Venkata Sivakumar, J. Mater. Sci. Lett. 10, 61 (1990).

${ }^{10}$ J. Pankert, J. Magn. Magn. Mater. 138, 45 (1994). 